Research Article

\title{
The Mechanical Criterion of Activation and Instability of Normal Fault Induced by the Movement of Key Stratum and Its Disaster-Causing Mechanism of Rockburst in the Hanging Wall Mining
}

\author{
Lyu Pengfei $\mathbb{D}^{1,2}$ Lu Jiabin, ${ }^{3}$ Wang Eryu, ${ }^{1,2}$ and Chen Xuehua ${ }^{4}$ \\ ${ }^{1}$ Mining Research Institute, Inner Mongolia University of Science and Technology, Baotou, \\ Inner Mongolia Autonomous Region 014010, China \\ ${ }^{2}$ Institute of Mining and Coal, Inner Mongolia University of Science and Technology, Baotou, \\ Inner Mongolia Autonomous Region 014010, China \\ ${ }^{3}$ Beijing Tiandi Huatai Mining Management Co., Ltd., Beijing, 100000, China \\ ${ }^{4}$ College of Mining, Liaoning Technical University, Fuxin, Liaoning Province 123000, China
}

Correspondence should be addressed to Lyu Pengfei; 2018930@imust.edu.cn

Received 27 November 2020; Revised 11 January 2021; Accepted 30 January 2021; Published 10 February 2021

Academic Editor: Hualei Zhang

Copyright (C) 2021 Lyu Pengfei et al. This is an open access article distributed under the Creative Commons Attribution License, which permits unrestricted use, distribution, and reproduction in any medium, provided the original work is properly cited.

Coal mine rockburst is closely related to the complex geological structure. Understanding the criterion of the fault activation instability and the disaster-causing mechanism of rockburst under the influence of mining is the theoretical premise and important guarantee of safe and efficient coal mining. In this paper, based on the theory of key stratum, the mechanical model of fault slip instability in the normal fault during the hanging wall mining was established, and the instability criterion was derived. It is concluded that the fault slip instability of the hanging wall is mainly controlled by two factors: (1) the distance between coal seams and key stratum and (2) the distance between working face and fault. Moreover, these two factors have an inverse relation to the occurrence of rockburst. Subsequently, three conceptual models of rockburst induced by the fault stress transfer, stress concentration of coal pillars, and fault structural instability were proposed. Based on the rock mechanics theory, the rockburst carrier system model of "roof-coal seam-floor" near the fault was established. The mechanical essence of fault rockburst was obtained as follows: under the action of fault, the static load of fault coal pillar was increased and superimposed with the fault activation dynamic load, leading to high-strength rockburst disaster. Based on the occurrence mechanism of fault rockburst, the monitoring and prevention concept and technical measures were proposed in three aspects, including the monitoring and control of fault activation dynamic loads, the monitoring of high static load in fault coal pillar and stress release, and the strengthening roadway support. These prevention and control measures were verified in the panel $103_{\text {down }} 02$ of the Baodian Coal Mine in engineering, and the effectiveness of these measures was proved.

\section{Introduction}

Coal is one of the important basic energies for China and global economic construction, accounting for more than $30 \%$ of the total global energy consumption [1]. In 2017, the total global coal production reached 5.481 billion tons, with a year-on-year increase of $3.4 \%$ and a sustained growth trend $[2,3]$. In the same year, China's coal production reached
2.541 billion tons, accounting for $46.4 \%$ of the total global coal production, ranking first in the world $[4,5]$. It can be seen that in a long period, coal resources will act as the most important basic energy in China's energy consumption structure. More than $95 \%$ of China's coal production comes from underground mines $[6,7]$. Underground coal mining usually faces complex geological and mining conditions. Rockburst occurs frequently, and its intense is also high. 
[8-10]. Besides, shallow coals are gradually exhausted; the deep mining geological conditions are more complex; faults, folds, and other geological structures are concentrated, and the development situation of coal resources is extremely severe [11-14]. The study has shown that the occurrence of coal mine rockburst is closely related to geological structure and other factors; it is easy for rockburst to enter the concentrated burst, especially in the vicinity of faults [15-18]. Faults are the most common geological structures in coal mining. The rockburst induced by fault activation belongs to structural instability disaster and has the following characteristics: the large burst amount of coal rock, strong destruction, rapid occurrence, and unclear precursor information [19-23]. In recent years, research on fault rockburst has been widely performed. Generally, the occurrence principle of fault rockburst is explained as follows: coal mining, blasting vibration, and other engineering activities induce the typical fault activation; when the fault activation degree is large, the hanging and foot walls of the fault move relatively, accompanied by a large energy mine earthquake; as a result, the shock instability of coal rock is directly induced or induced with the superimposition of mining stress. The principle is shown in Figure 1.

The mechanical model is an important theoretical research method to reveal the mechanism and criterion of fault rockburst. In China and other foreign countries, Pan Dai et al. $[24,25]$ put forward the disturbance response criterion for fault rockburst and considered that the increase of shear stress and the decrease of normal stress on the fault plane are the main reasons for the occurrence of fault rockburst, and the interaction between the medium of the fault zone and its surrounding rock mechanical properties is the secondary reason affecting the occurrence of fault rockburst. In this way, the criterion of fault disturbance response well explains the influencing factors and mechanism of rockburst induced by fault instability, and it is the combination and extension of the elastic rebound theory proposed by Carpinteri and Borla in 1951 [26] and the stick-slip theory proposed by Brace and Byerlee in 1966 [27]. Li et al. [28] established the mechanical model of fault structural locking and unlocking slip and theoretically derived the judgment equations of fault upward unlocking and downward unlocking. In these functions, fault unlocking is related to fault friction strength, fault dip angle, and the ratio of horizontal stress to vertical stress. Through the monitoring of point stress and point displacement, Michalski [29] discovered that the stress near the fault rises and falls sharply, and the risk of rockburst increases when the working face is near the fault. At present, microseismic monitoring is the most effective dynamic response monitoring method of coal rock and has been widely used in the monitoring and prevention of the fault rockburst. Chen et al. [30] analyzed the influence of fault structural plane on mine pressure distribution and roof stability of mining face through microseismic monitoring. It was concluded that when the working face was advanced to the high-stress concentration area of the fault, the peak value of advanced abutment pressure of the working face decreases and the roof stability is poor.
In conclusion, the mechanical model of fault instability criterion can be used to quantitatively judge the activity of fault in theory, but most of them are based on seismic mechanism. The roof movement, especially the movement and fracture of the key stratum of the roof, is rarely considered as the active occurrence condition of fault activation instability. In view of this, the mechanics model of the key stratum movement of the roof was established, and then the mechanical criterion of the activation instability of normal faults in the key stratum was derived. On this basis, the mechanical essence of the occurrence of the fault rockburst was discussed based on rock mechanics. Then, a new concept of the prevention and control of the fault rockburst was proposed based on the abovementioned research results, and the prevention and control measures were applied to the engineering.

\section{Mechanical Criterion of Activation and Instability of Normal Fault Induced by Key Stratum Movement in the Hanging Wall}

The key stratum refers to a hard and thick rock layer that controls the overburden in the roof of the working face [31]. In conventional mining, the strata are hard to break; once broken, the released energy is extremely huge. Therefore, the movement state of the overburden depends on the location, properties, and periodic fracture characteristics of the key stratum. As a geological weak plane, faults cut off the mechanical connection between the key stratum and the rock mass ahead and change the mechanical occurrence state of the key stratum. When the key stratum and normal faults exist at the same time, the stress situation of "masonry beam structure" can be formed by mining-induced overburden movement, as shown in Figure 2.

The fault plane is defined as the $y$-axis of the rectangular coordinate system, and $F_{\mathrm{N}}$ and $T$ are decomposed along the fault plane:

$$
\left\{\begin{array}{l}
F_{x}=F_{\mathrm{N}} \cos \theta+T \sin \theta, \\
F_{y}=F_{\mathrm{N}} \sin \theta-T \cos \theta,
\end{array}\right.
$$

where $F_{\mathrm{N}}$ is the self-supporting force of block $\mathrm{A}$ in the key stratum of the fault plane, $\mathrm{kN} ; T$ is the horizontal extrusion force of block A on the fault plane, $\mathrm{kN} ; \theta$ is the fault dip angle, $\left({ }^{\circ}\right)$; and $F_{x}$ and $F_{y}$ are the resultant forces in $x$ and $y$ directions at the fault plane, $\mathrm{kN}$.

According to the previous studies [32], the stress condition that the fault does not slip at the key stratum is $F_{x} \tan \varphi$ $\geq F_{y}$, which can be further deduced as the following equation:

$$
\frac{F_{\mathrm{N}}}{T}<\cot (\theta-\varphi)
$$

where $\varphi$ is the internal friction angle of rock mass near the fault, $\left(^{\circ}\right)$.

From equation (1), it can be seen that $F_{x}>0$ is constant, that is, the contact between the key stratum and the fault plane will not separate due to mining; whether the key stratum slides upward or downward at the fault plane depends on the horizontal squeezing force $T$. 

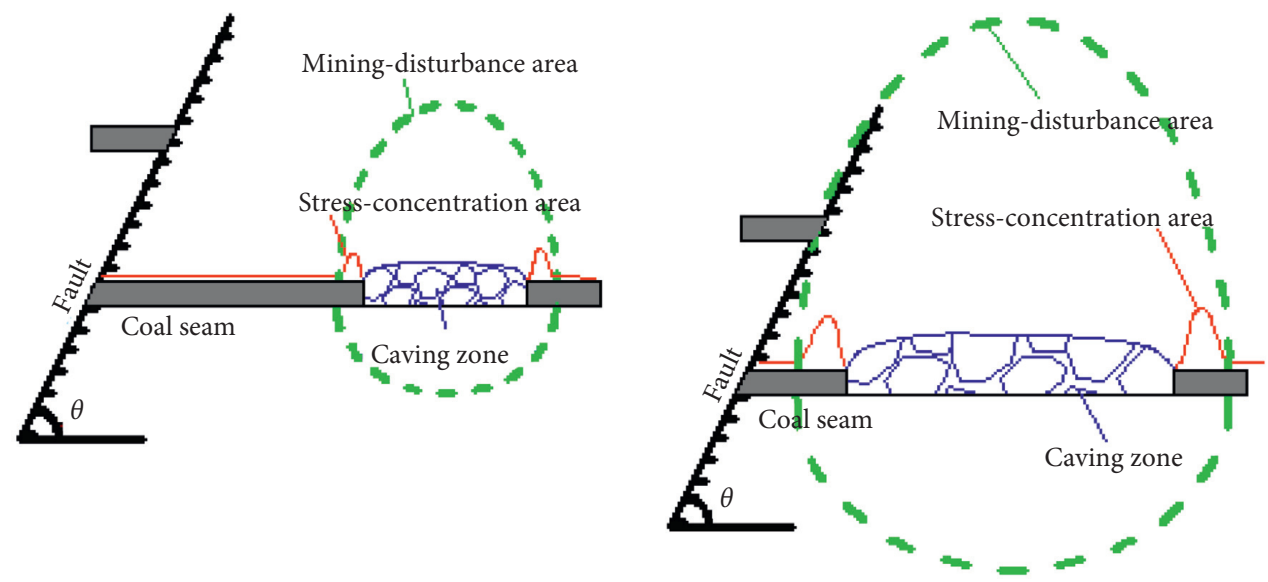

(a)

(b)

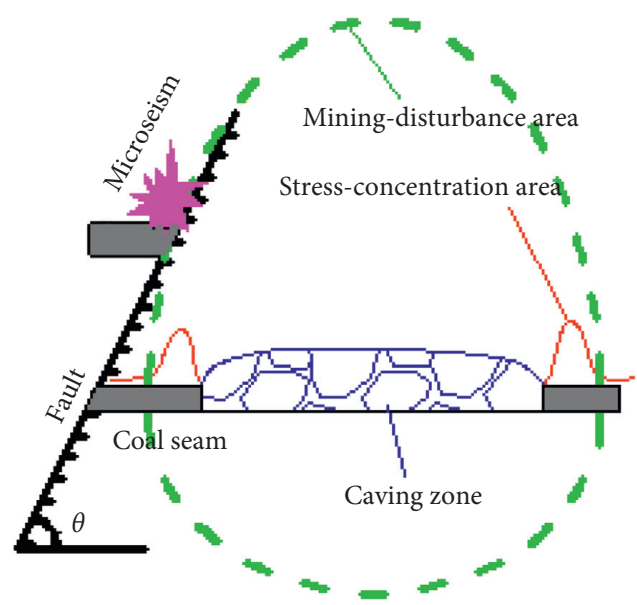

(c)

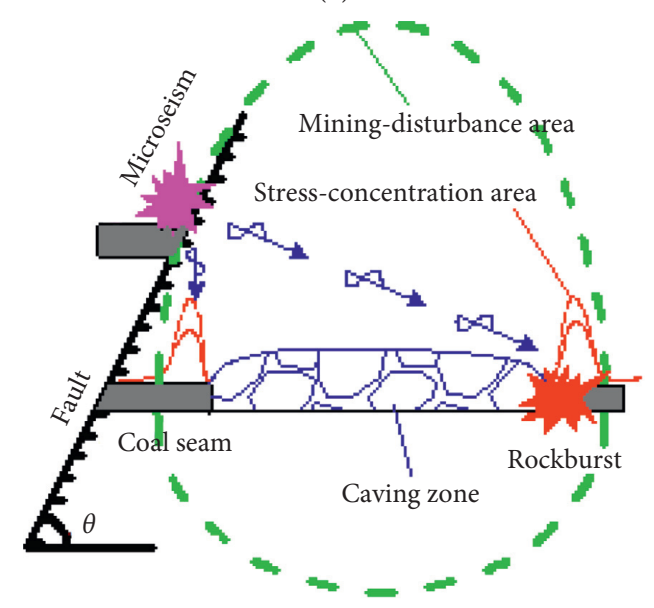

(d)

FIGURE 1: Fault mining activation and its induced mine earthquake and rockburst principle. (a) Mining does not affect the fault; (b) fault activation induced by mining; (c) mine earthquake induced by fault activation; (d) rockburst induced by mine earthquake.

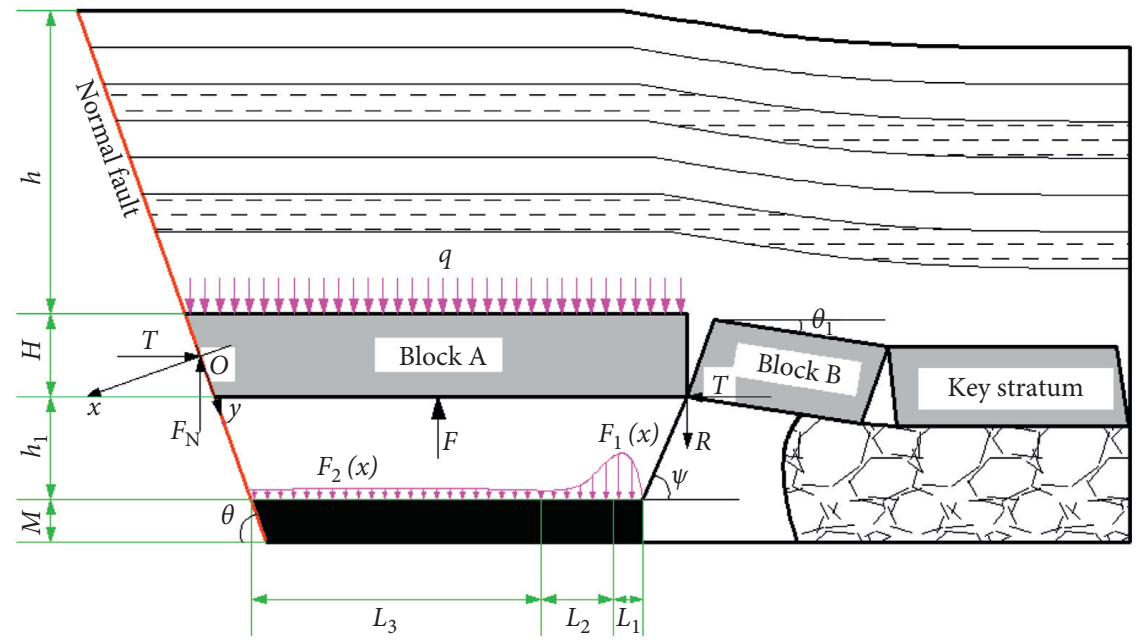

FIGURE 2: Movement mode and stress state of key stratum of normal fault in the hanging wall mining. 
Taking the width of the key rock mass as 1, the stress analysis of rock block A in the key stratum can be obtained as the following equation:

$$
\left\{\begin{array}{c}
F_{\mathrm{N}}=\lambda(h+H)\left(h_{1} \cot \theta+L_{1}+L_{2}+h_{1} \cot \psi\right)+R-F, \\
F=\int_{0}^{L_{1}} F_{1}(x) \mathrm{d} x+\int_{0}^{L_{2}} F_{2}(x) \mathrm{d} x+\int_{0}^{L_{3}} F_{2}(x) \mathrm{d} x-\gamma V, \\
V=\left(h_{1} \cot \theta+2 L_{1}+2 L_{2}+2 L_{3}+h_{1} \cot \psi\right) \frac{h_{1}}{2},
\end{array}\right.
$$

where $\gamma$ is the average unit weight of overburden on the working face, $\mathrm{kN} / \mathrm{m}^{3} ; h$ is the distance between the key stratum and the surface, $m$; $H$ is the thickness of the key stratum, $m ; h_{1}$ is the thickness of the weak rock layer under the key stratum, $m$; $V$ is the volume of the rock layer between the key stratum and the coal seam, $\mathrm{m}^{3} ; L_{1}$ is the width of the limit equilibrium zone of the fault coal pillar, $m ; L_{2}$ is the width of the elastic zone of the fault coal pillar, $m ; L_{3}$ is the distance from the original rock stress area to the fault, $m$; $\Psi$ is the falling angle of rock mass under the key stratum, $\left({ }^{\circ}\right) ; R$ is the shear force of rock block $\mathrm{B}$ to rock block $\mathrm{A}, \mathrm{kN} ; \mathrm{F}$ is the supporting force of rock mass in the lower part of key stratum to key stratum, $\mathrm{kN} ; F_{1}(x)$ is the advanced abutment pressure of the working face, $\mathrm{kN}$; and $F_{2}(x)$ is the roof pressure of coal seam in the original rock stress area, $\mathrm{kN}$.

According to the previous study [33], the advanced abutment pressure $F_{1}(x)$ of the working face and the roof pressure $F_{2}(x)$ of the coal seam in the original rock stress area meet the following equation:

$$
\left\{\begin{array}{l}
F_{1}(x)=\tau_{0} \cot \varphi \frac{1+\sin \varphi_{1}}{1-\sin \varphi_{1}} \mathrm{e}^{(2 f / M)(1+\sin \varphi / 1-\sin \varphi)} L_{1} \quad\left(0 \leq x \leq L_{1}\right), \\
F_{1}(x)=k \gamma\left(h+H+h_{1}\right) \mathrm{e}^{(2 f / M \beta)\left(L_{1}-x\right)} L_{2} \quad\left(L_{1} \leq x \leq L_{2}\right), \\
F_{2}(x)=\gamma\left(h+H+h_{1}\right) L_{3},
\end{array}\right.
$$

where $M$ is the coal seam thickness, $m ; f$ is the friction coefficient between coal seam and roof, generally $0.015-0.035 ; \varphi_{1}$ is the internal friction angle of coal, $\left(^{\circ}\right) ; k$ is the leading stress concentration coefficient of the working face; $\tau_{0}$ is the shear strength of coal, $\mathrm{kPa} ; \beta$ is the lateral pressure coefficient of coal seams, generally ranging from $0.8-1.5$.

According to $[34,35]$, the expressions of horizontal compression force $T$ of fault plane block A and shear force $R$ of key layer rock block B on key layer rock block A are shown in the following equation:

$$
\left\{\begin{array}{l}
T=\frac{\left(\gamma h L \sin \theta_{1}\right)}{\left((4 H / l)-\sin \theta_{1}\right)} \\
R=\frac{\left((4 H / l)-3 \sin \theta_{1}\right) \gamma h L}{\left((4 H / l)-\sin \theta_{1}\right)}
\end{array}\right.
$$

where $l$ is the average length of the key rock block formed by the fracture of the key stratum, $m$, and $\theta_{1}$ is the angle of the key rock block $\mathrm{A},\left(^{\circ}\right)$.

Then, the rotation angle $\theta_{1}$ of key rock block A satisfies the following equation:

$$
\sin \theta_{1}=\frac{1}{l}\left[M-h_{1}(k-1)\right]
$$

According to equations (3)-(6) and the substitution of equation (2), it can be seen that the key stratum is not activated and unstable at the fault, and the conditions to be met are in the following equation:

$$
\frac{F_{N}}{T}=\frac{\left.\left(4 H-2 M+2 h_{1}(k-1)\right] \times\left\{\begin{array}{r}
\gamma(h+H) \times\left(h_{1} \cot \theta+L_{1}+L_{2}+L_{3}+h_{1} \cot \psi\right)+ \\
0.5 \gamma h_{1}\left(h_{1} \cot \theta+2 L_{1}+2 L_{2}+2 L_{3}+h_{1} \cot \psi\right)- \\
\gamma\left(h+H+h_{1}\right) L_{3}-\tau_{0} \cot \varphi_{1} L_{1} M / 2 f\left(e^{(2 f / M)\left(1+\sin \varphi_{1} / 1-\sin \varphi_{1}\right)}-1\right)- \\
k \gamma\left(h+H+h_{1}\right) \times L_{2}\left[M \beta / 2 f e^{(2 f / M \beta) L_{1}}-M \beta / 2 f e^{(2 f / M \beta)\left(L_{1}-L_{2}\right)}\right]
\end{array}\right]\right)}{\left\{\gamma h l\left[M-h_{1}(k-1)\right]\right\}<\cot (\theta-\varphi)}
$$

where $\theta$ is the fault dip angle, and $\theta=72^{\circ} ; \varphi$ is the internal friction angle of the rock mass near the fault, and $\varphi=18^{\circ} ; H$ is the thickness of the key stratum, and $H=42.8 \mathrm{~m}$; $M$ is the thickness of the coal seam, and $M=6.5 \mathrm{~m}$; $h$ is the distance between the key stratum and the surface, and $h=500 \mathrm{~m} ; h_{1}$ is the distance between the coal seam and the key stratum, and $h_{1}=60 \mathrm{~m} ; k$ is the advanced stress concentration factor of the working face, and $k=2 ; \gamma$ is the average unit weight of 
overburden on the working surface, and $\gamma=25 \mathrm{kN} / \mathrm{m}^{3}$; $\Psi$ is the falling angle of rock mass at the lower part of key stratum, and $\Psi=75^{\circ} ; L_{1}$ is the width of limit equilibrium zone of working face, and $L_{1}=5 \mathrm{~m} ; L_{2}$ is the width of elastic zone of working face, and $L_{2}=15 \mathrm{~m} ; \tau_{0}$ is the shear strength of coal body, and $\tau_{0}=2500 \mathrm{kPa} ; \varphi_{1}$ is the internal friction angle of coal, and $\varphi_{1}=23^{\circ} ; f$ is the friction coefficient between coal seam and roof, and $f=0.02$; and $\beta$ is the lateral pressure coefficient of coal seams, and $\beta=1$. Through the calculation, when the working face is $48.42 \mathrm{~m}$ away from the fault (i.e., $L_{1}+L_{2}+L_{3}=48.42 \mathrm{~m}$ ), the key stratum is activated and unstable at the fault, which also shows that the $50 \mathrm{~m}$ fault protection coal pillar in the working face 5318 is reasonable. According to the abovementioned values, the distance $h_{1}$ between the coal seam and the key stratum and the distance $L_{3}$ from the original rock stress area to the fault in equation (7) are regarded as independent variables. At the dip angle of $72^{\circ}$, the influence relationship of the fault activation instability and the two factors ((1) the distance between the coal seam and the key stratum and (2) the distance between the working face and the fault) is obtained, as shown in Figure 3. The filling part in Figure 3 meets the condition of fault instability. It can be seen that the critical condition of fault activation and instability is inversely proportional to the abovementioned two factors when other conditions remain unchanged.

\section{Mechanism of Rockburst Induced by Fault Activation}

The fault is a common geological structure in coal mining. Its unique discontinuous structure controls the deformation, failure, and mechanical properties of the coal rock. The interaction between the fault, coal mining activities, and key stratum movement induced by the mining is the key to fault activation. After fault activation, the dynamic load is transferred and released and superimposed with the dynamic and static load of mining, which may induce the rockburst disaster. According to the distance between fault and working face in the field investigation, the mechanism of fault activation induced by coal mining activities is summarized into three conceptual models, as shown in Figure 4.

(1) The model of rockburst is induced by fault stress transfer (Figure 4(a)). When the mining activity is far away from the fault (normal fault, usually greater than $60 \mathrm{~m}$ ), the fault activation dynamic load, fault coal pillar static load, and mining stress almost have no influence on each other. At this time, the fault activation degree is low, but some fault stresses still transfer to the mining space and overlap with the advanced abutment pressure. When the advanced abutment pressure of the working face is high, the rockburst is easily induced. This kind of rockburst appears in the peak stress area in front of the working face.

(2) The model of rockburst is induced by stress concentration of fault coal pillar (Figure 4(b)). As the fault cuts off the continuity of coal seam and roof and

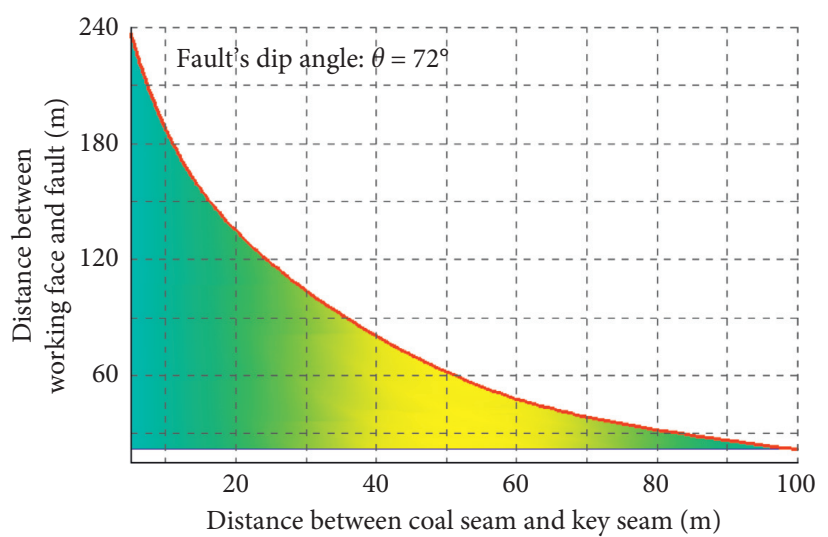

FIgURE 3: Critical conditions of fault activation and instability at the dip angle of $72^{\circ}$.

floor, the fault coal pillar is formed when the distance between working face and fault decreases with mining activities. At this time, the double effects of rotary subsidence of the roof rock block and advanced abutment pressure force the fault coal pillar static load to be highly concentrated. If the fault activation dynamic load and the highly concentrated coal pillar static load are superimposed again, it is very easy to induce the fault coal pillar rockburst with the large damage degree and scope. Therefore, this is the key period of the prevention and control of the fault rockburst. This kind of rockburst usually appears in the coal rock between the working face and the fault.

(3) The model of rockburst is induced by the fault instability (Figure $4(\mathrm{c})$ ). When the working face is close to the fault (normal fault, usually less than $20 \mathrm{~m}$ ), long-term activation forces the fault layer to increase the sliding property, and the relative movement trend of the hanging wall and footwall of the fault increases under the action of roof pressure. The overall structure of the fault is easy to lose stability and induce rockburst. The intensity of this kind of impact disaster is between the above two situations, and the location of rockburst is mostly near the fault zone.

\section{Monitoring and Prevention of Fault Rockburst}

4.1. Concepts and Technical Measures. According to the three conceptual rockburst models of fault activation described in the previous section, the prevention and control of fault rockburst should start from three aspects: weakening the fault activation dynamic load, releasing the high static load of fault coal pillar and strengthening roadway support. Feasible monitoring and control measures are summarized as follows.

4.1.1. Fault Activation Dynamic Load Monitoring and Control. Mining engineering activities induce fault activation, and the fault stress is mostly released in the sudden 


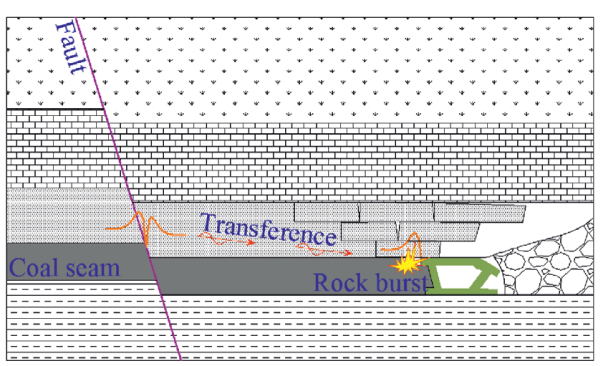

(a)

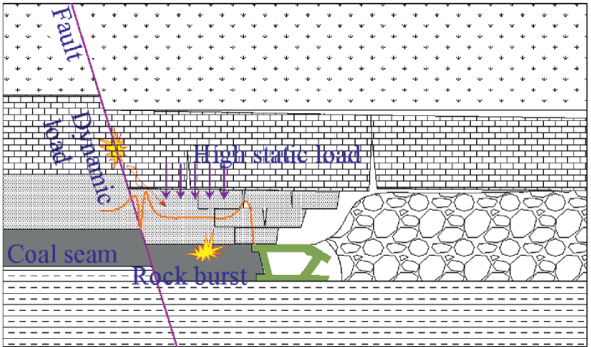

(b)

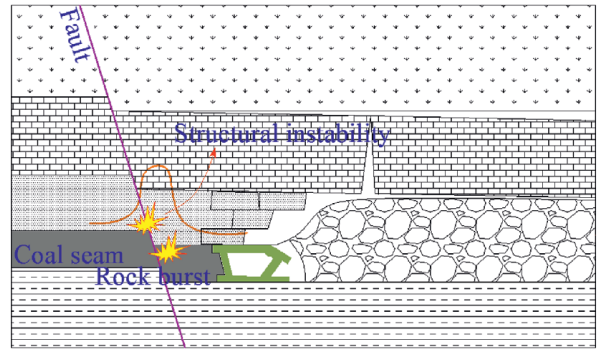

(c)

Figure 4: Conceptual model of rockburst induced by fault activation. (a) Fault stress transfer. (b) Stress concentration of fault coal pillar. (c) Instability of fault.

form of dynamic load. Therefore, the instantaneous information capture method such as microseismic is mainly used to monitor the fault activation dynamic load. To prevent and control the fault activation dynamic load, some measures such as large diameter borehole pressure relief and coal seam water injection can be used to directly reduce the cohesive force and friction angle of the fault plane, so as to weaken the release strength of fault activation dynamic load; the disturbance intensity of dynamic load can also be reduced by controlling the mining speed of working face and the roof cutting.

4.1.2. High Static Load Monitoring and Stress Release of Fault Coal Pillar. To monitor the static load of fault pillar, the stress and fracture information between fault and working face can be directly obtained by drilling cuttings method, borehole stress monitoring, microseismic monitoring, surface displacement monitoring, and other conventional methods; roof movement and overlying rock structure evolution information can be inferred by using support working resistance monitoring, and coal pillar static load information under coupling effect of fault and roof structure can also be obtained indirectly. Large diameter borehole pressure relief and deep hole pressure relief blasting can be used to release the high static load of fault coal pillar.

4.1.3. Strengthening Roadway Support. Strengthening the supporting strength of the roadway between fault and working face is an effective method of in-situ rockburst prevention, which can not only provide higher lateral constraints for roadway side but also improve the compressive strength and antirockburst capability of coal rock. In this way, the coal rock between the fault and the working face is not easy to be damaged. Even if the failure occurs, most of the energy can be released in the form of damage and fracture of coal rock in the transmission process, so as to avoid the occurrence of rockburst disaster. Hu et al. [36] also put forward technical measures to prevent rockburst by improving roadway support strength.

4.2. Engineering Cases. Baodian Coal Mine in Yanzhou mining area of China has a typical tendency of rockburst. The coal seam 3 down was the main mined area of panel $103_{\text {down }} 01$, with an average coal thickness of $5.9 \mathrm{~m}$ and an average dip angle of $2^{\circ}$. In the north, there was panel $103_{\text {down }} 02$, and the southern part was the solid coal. The strike length of the working face was $978 \mathrm{~m}$ and the inclined length was $225 \mathrm{~m}$. There was a hard layer of $21.5 \mathrm{~m}$ thick glutenite at $45 \mathrm{~m}$ above the coal seam, which was the key stratum that dominated the overburden movement of the working face. A normal fault LF21 was distributed in the south, and the working face was located in the hanging wall of the normal fault. The roadway layout of the working face and the location relationship with the normal fault LF21 are shown in Figure 5. The fault LF21 had a strike length of $2.4 \mathrm{~km}$ and was distributed along the east-west direction. The dip angle of the fault was about $66^{\circ}$ and the drop was about $23 \mathrm{~m}$ near the $103_{\text {down }} 01$ working face. As the distance between the mining face and the working face decreased, the minimum plane distance between them was $30 \mathrm{~m}$, which was equivalent to the working face mining toward the fault. Therefore, a seismological observation system (SOS) was installed before the mining of the panel $103_{\text {down }} 01$ to realize the real-time capture of surrounding rock movement and the activation information of fault LF21. 


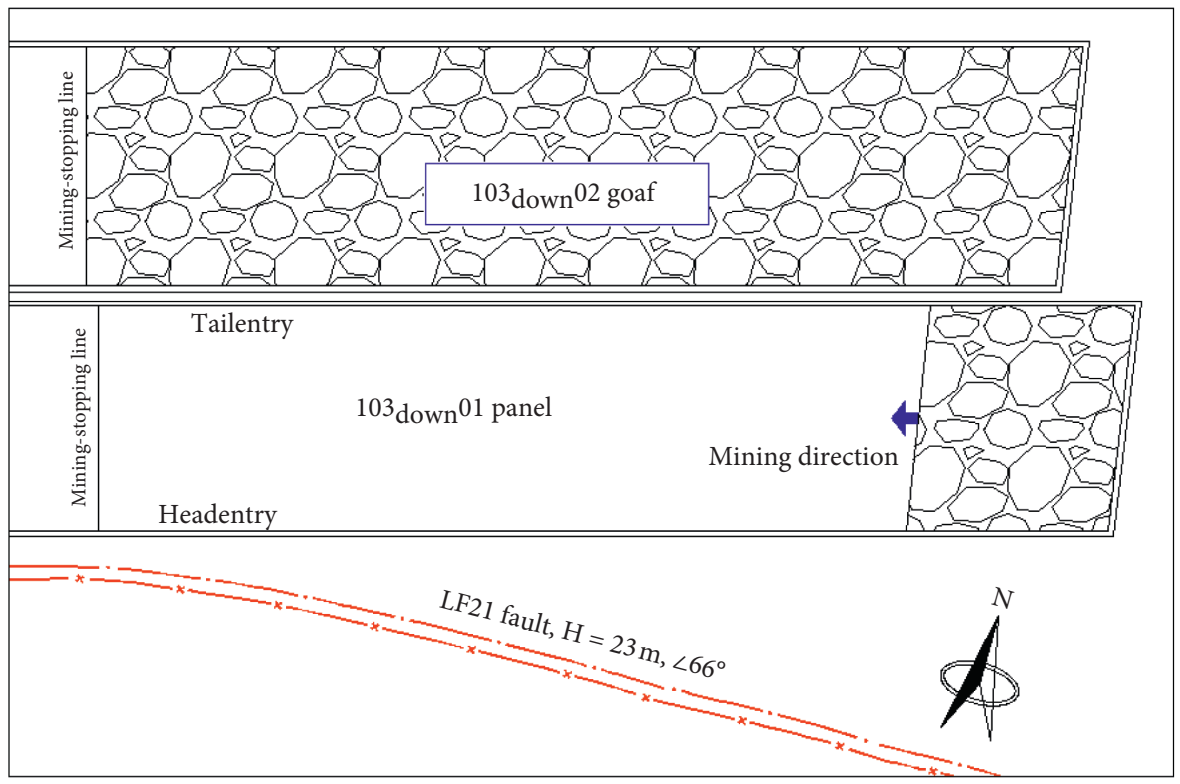

FIgURE 5: Layout of the roadway and its relationship with fault location in panel $103_{\text {down }} 01$.

The mining of panel $103_{\text {down }} 01$ was started on June 17 , 2014. As of September 29, 2014, the mining of panel was $440 \mathrm{~m}$, and microseismic events began to appear near the fault LF21. At this time, the shortest distance between the panel and fault LF21 was $142.5 \mathrm{~m}$. The focal distribution of the panel from the beginning of mining to $440 \mathrm{~m}$ of mining is shown in Figure 6. It can be seen that the distribution of microseismic sources basically conforms to the conventional characteristics, that is, most of them are distributed in the goaf of this panel and its adjacent panels. However, on September 27, 2014, and September 29, 2014, two consecutive seismic events with energy greater than $10^{6} \mathrm{~J}$ occurred near the fault LF21, indicating that the fault LF21 was activated to a certain extent and had the risk of inducing rockburst. If the panel continues to advance, the width of the fault coal pillar will gradually reduce, the static load and dynamic load strength of the fault coal pillar will inevitably increase, and the possibility of inducing rockburst will be enlarged. Therefore, the mining was immediately terminated, and experts were organized to analyze the causes and formulate the hazard relief schemes. Combined with the prevention and control concept of fault rockburst, technical measures, and equipment installation conditions of the panel, the following three hazard relief measures were finally determined.

4.2.1. Coal Seam Water Injection. Coal seam water injection can soften the coal body, change the coal fracture structure, reduce the static load accumulation capacity and elastic energy reserve capacity of the coal rock, and weaken coal strength and rockburst tendency. During the stop-production of the panel $103_{\text {down }} 01$, six water injection drilling fields were arranged within the range of $440-978 \mathrm{~m}$ in the headentry, with a spacing of $90 \mathrm{~m}$. In the 3 drilling fields near the panel and the 3 drilling fields near the stop-production line, 9 and 5 boreholes were arranged in a radial single row along with the seam inclination.
The depth of the boreholes was $60-130 \mathrm{~m}$, the diameter of the boreholes was $100 \mathrm{~m}$, the high-pressure water injection pressure was $16 \mathrm{MPa}$, and the static pressure water injection pressure was $5 \mathrm{MPa}$. After water injection, the measured value of the water content of coal increased from $4.6 \%$ to $9.7 \%$, and the effect of water injection was significant.

4.2.2. Large Diameter Borehole Pressure Relief. Large diameter borehole pressure relief can release the concentrated load of fault coal pillar, transfer the high-stress area on both sides of roadway to the deep coal body, and weaken the rockburst disaster. After the completion of coal seam water injection in the panel103 $3_{\text {down }} 01$, the pressure relief measures of large diameter boreholes were implemented on the two sides of the remaining transport gateway. The parameters of pressure relief boreholes are shown in Figure 7.

4.2.3. Strengthening Roadway Support. Strengthening roadway support can effectively improve the lateral restraint of the roadway in the impact zone and enhance the impact resistance of the roadway. An additional ZT45000/24/75 hydraulic support for advanced support was installed in the headentry during the mining of the remaining coal of the panel103 down 01 to enhance the support strength in the advance stress area, as shown in Figure 8.

After the implementation of the abovementioned measures, the drilling cuttings method was used to test the prevention and control effect of rockburst on the transport gateway. After confirming that there was no impact risk, the mining was started again on February 13, 2015. The mining speed was adjusted from the original $5.8-7.6 \mathrm{~m} / \mathrm{d}$ to $3.8-4.5 \mathrm{~m} / \mathrm{d}$, and the mining speed was kept at a constant speed. Figure 9 shows the distribution of microseismic sources during the mining period of the remaining panel of $103_{\text {down }} 01$. As shown in Figure 9(a), 


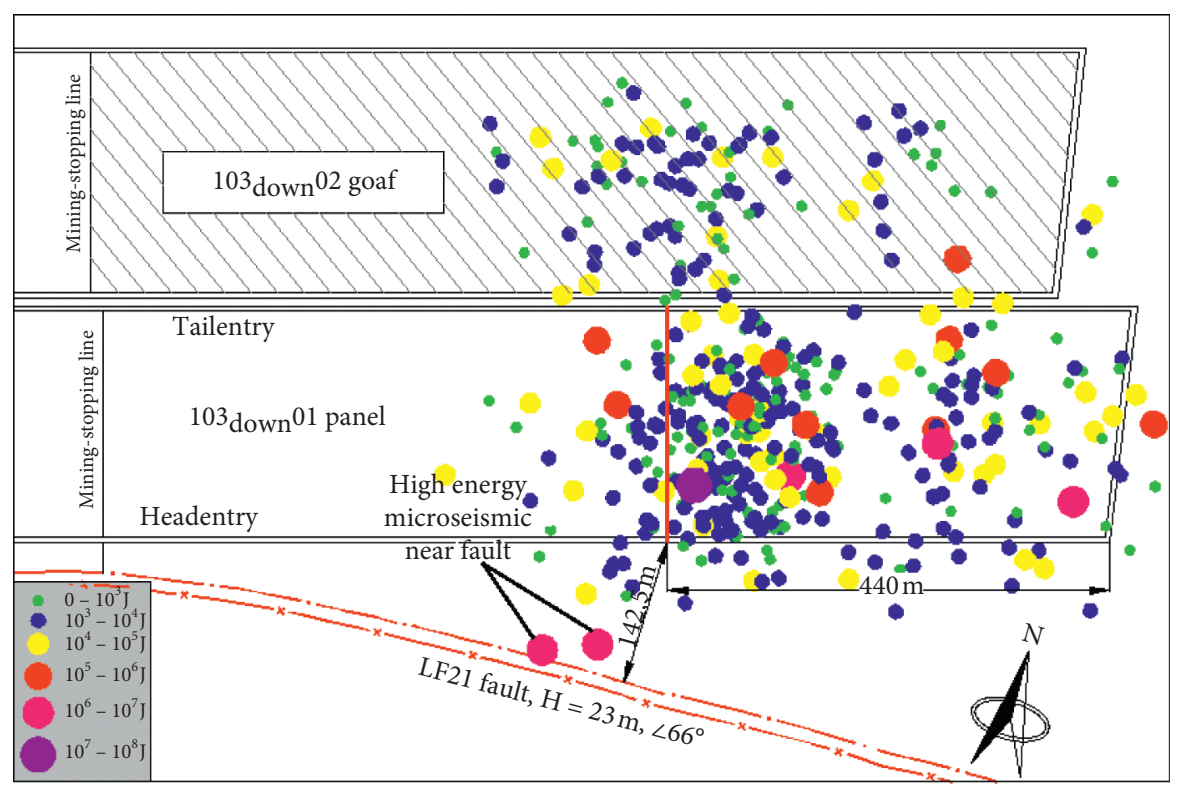

FIgURe 6: Seismic source distribution from 0-440 m mining (June 17, 2014, to September 29, 2014).

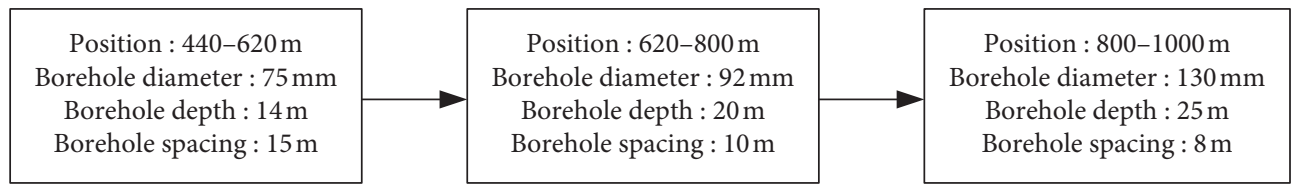

Figure 7: Parameters of large diameter borehole pressure relief.

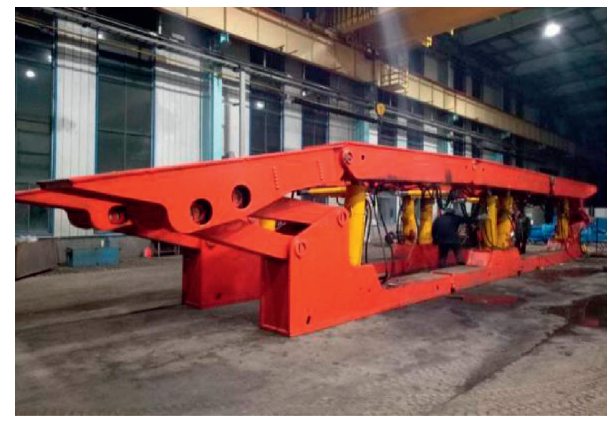

Figure 8: ZQ4000/20.6/75 advanced support hydraulic support.

during the mining period of 440-573 m, compared with the previous mining period, the small energy microseisms in this stage are significantly increased, and there was no seismic source distribution near the fault. It indicates that the high-pressure water injection and borehole pressure relief measures effectively release the elastic energy of coal rock and promote the generation of a large number of microcracks in the coal rock. Then, small energy microseismic events were induced by the expansion of microcracks under the influence of mining disturbance. During the mining of the remaining panel, there were still large energy microseismic events, but the source location was basically in the goaf of the panel. Therefore, it is believed that this was induced by the fracture of key stratum in roof. When the mining was advanced to the stop line of the panel (Figure 9(d)), the high-energy microseisms increased again. At this time, the distance between the panel and the fault was $30-50 \mathrm{~m}$, and the fault activity was enhanced again. Therefore, the mining speed was reduced again and strictly controlled below $4 \mathrm{~m} / \mathrm{d}$ until the panel was fully mined, and there was no rockburst disaster. The governance goal of earthquake and disaster-free was 


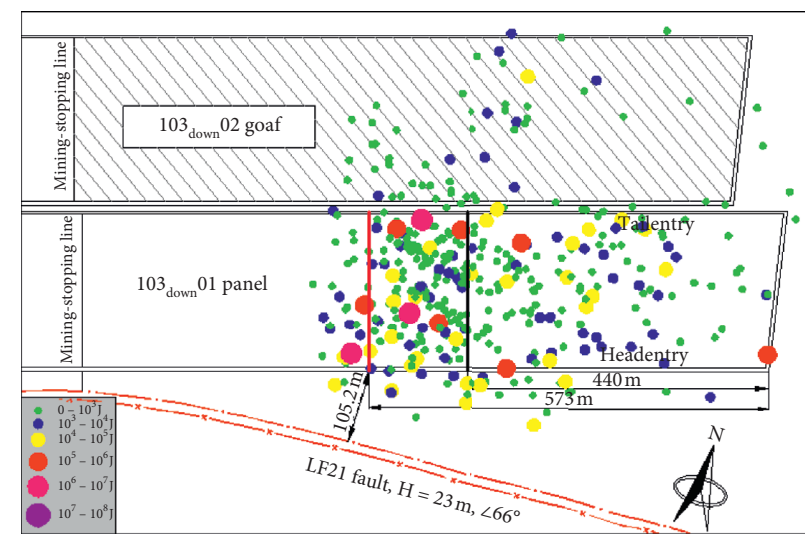

(a)

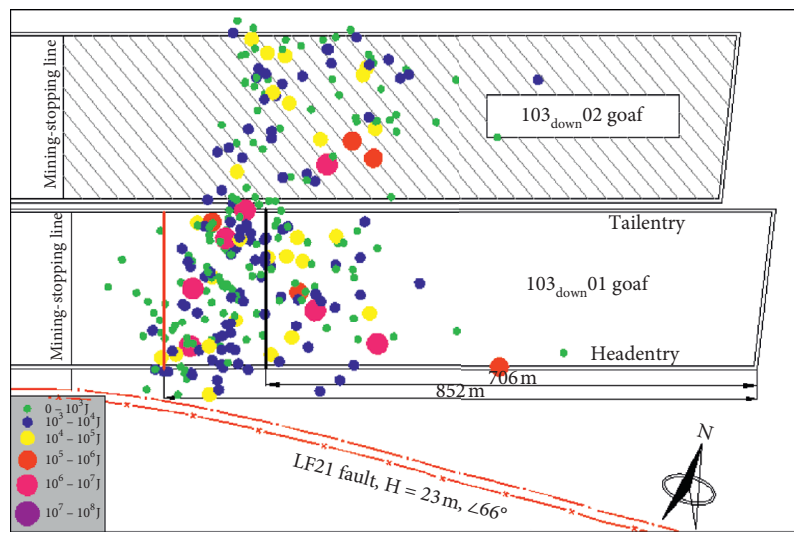

(c)

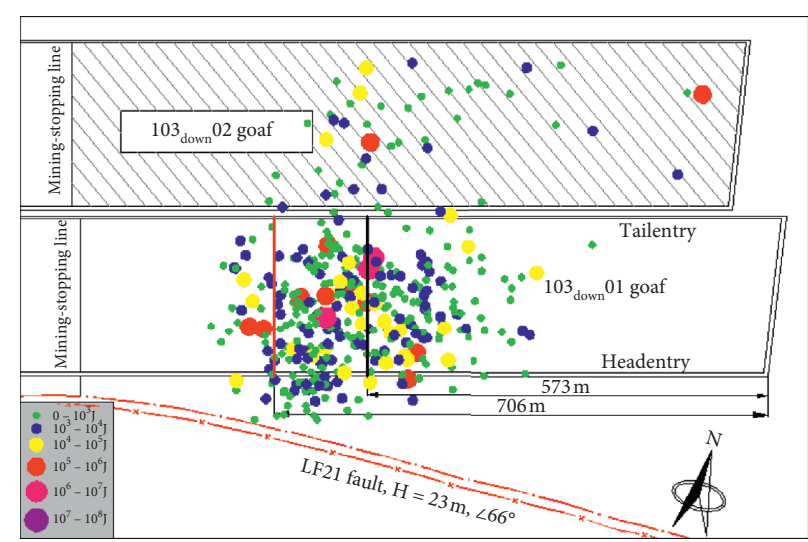

(b)

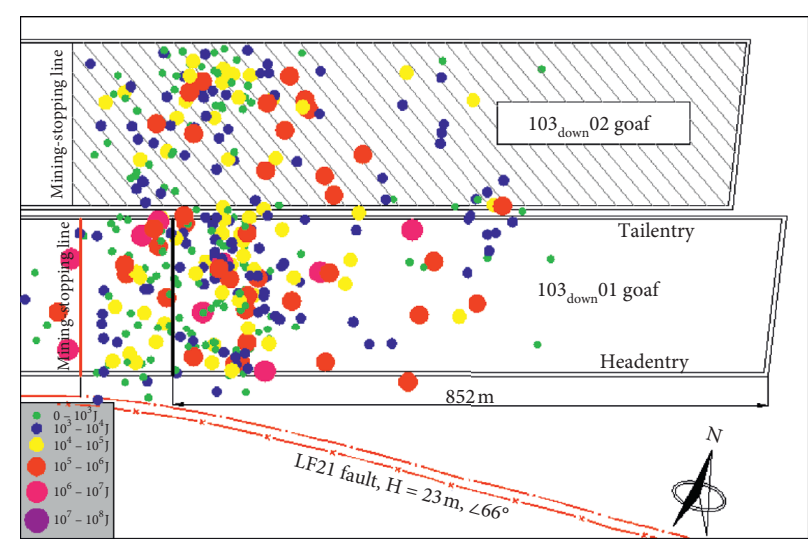

(d)

FiguRE 9: Seismic source distribution of the remaining panel during mining (February 13, 2015, to August 4, 2015). (a) Mining 440-573 m; (b) mining 573-706 m; (c) Mining 706-852 m; (d) mining 852-978 m.

realized. It also shows that the proposed prevention and control concept and measures of fault rockburst above are effective.

\section{Conclusion}

To control the frequent occurrence of rockburst disasters in mining coal seams in fault and other geological structure areas, the mechanism of fault activation and the mininginduced rockburst in the hanging wall mining of normal fault is studied based on theoretical analysis, mechanical model, and engineering cases. This study provides a reference for the prevention and control of fault rockburst. The main conclusions are as follows [36]:

(1) During the hanging wall mining, the mechanical model of fault activation in normal fault under the control of key roof strata is established, and the mechanical criterion of fault slip instability is derived. It is concluded that the critical condition of fault slip instability is mainly controlled by two factors: (1) the distance between coal seams and key stratum and (2) the distance between working face and fault; and the influence of these two factors is inversely proportional to the critical condition of fault slip instability.
(2) According to the distance between working face and fault, three conceptual models of rockburst induced by fault stress transfer, rockburst induced by stress concentration of fault coal pillar, and rockburst induced by the fault instability are proposed. Based on rock mechanics theory, the rockburst carrier system model of "roof-coal seam-floor" near the fault was established. The mechanical essence of fault rockburst was obtained as follows: under the action of fault, the static load of fault coal pillar was increased and superimposed with the fault activation dynamic load, leading to high-strength rockburst disaster. On this basis, based on the rock mechanics theory, the paper studies the rockburst carrier system model of "roof-coal floor" near the fault and reveals that the mechanical essence of fault rockburst is that the static load of fault coal pillar is increased under the action of fault, and the superposition of fault activation dynamic load leads to high-strength impact disaster.

(3) Based on the occurrence mechanism of fault rockburst, the monitoring and prevention concept and technical measures of this rockburst are proposed, including three aspects: fault activation dynamic load monitoring and control, fault coal pillar high 
static load monitoring and stress release, and strengthening roadway support. In panel $03_{\text {down }} 02$ of the Baodian Coal Mine, the proposed measures were verified in the engineering. The results show that after the implementation of the abovementioned measures, microseismic frequency and energy amplitude of the panel $03_{\text {down }} 02$ are significantly reduced. Therefore, the proposed prevention and control measures are proved to be effective.

\section{Data Availability}

The data used to support the findings of this study are included within the article.

\section{Conflicts of Interest}

The authors declare that they have no conflicts of interest.

\section{Acknowledgments}

The study of this paper was supported by the Natural Science Foundation of Inner Mongolia Autonomous Region (2019LH05005) and the Innovation Foundation of Inner Mongolia University of Science and Technology (2019QDLB32).

\section{References}

[1] R. C. Milici, R. M. Flores, and G. D. Stricker, "Coal resources, reserves and peak coal production in the United States," International Journal of Coal Geology, vol. 113, pp. 109-115, 2013.

[2] D. Ma, J. X. Zhang, H. Y. Duan et al., "Reutilization of gangue wastes in underground backfilling mining: overburden aquifer protection," Chemosphere, vol. 264, no. 1, Article ID 128400, 2021.

[3] P. F. Lyu, X. Y. Bao, G. Lyu, and X. H. Chen, "Research on fault activation law in deep mining face and mechanism of rockburst induced by fault activation," Advances in Civil Engineering, vol. 2020, Article ID 8854467, 13 pages, 2020.

[4] P. Kong, L. S. Jiang, J. M. Shu, and L. Wang, "Mining stress distribution and fault-slip behavior a case study of faultinfluenced long wallcoal mining," Energies, vol. 12, no. 10, p. 2494, 2019.

[5] H. Rong, S. Q. Yu, H. W. Zhang, and B. Liang, "Quantitative calculation of critical depth in typical rockburst mine," $A d$ vances in Civil Engineering, vol. 2020, Article ID 7968160, 9 pages, 2020.

[6] G. Dong, X. M. Liang, and Z. Wang, "The properties of a coal body and prediction of compound coal-rock dynamic disasters," Shock and Vibration, vol. 2020, Article ID 8830371, 2020.

[7] J. Guo, L. Ma, F. Ju, C. Zhang, F. Wang, and S. Guo, "Mechanism of dynamic failure in roadways with thick and competent roof strata: a case study," Advances in Civil Engineering, vol. 2019, Article ID 2618543, 15 pages, 2019.

[8] D. Ma, H. Duan, Q. Zhang et al., "A numerical gas fracturing model of coupled thermal, flowing and mechanical effects," Computers, Materials \& Continua, vol. 65, no. 3, pp. 21232141, 2020.

[9] B. Zhou, K. Qian, K. Qian, X. Ma, and X. Dai, "Ellipsoidal bounding set-membership identification approach for robust fault diagnosis with application to mobile robots," Journal of Systems Engineering and Electronics, vol. 28, no. 5, pp. 986995, 2017.

[10] D. Ma, H. Duan, W. Liu, X. Ma, and M. Tao, "Water-sediment two-phase flow inrush hazard in rock fractures of overburden strata during coal mining," Mine Water and the Environment, vol. 39, no. 2, pp. 308-319, 2020.

[11] S. He, D. Song, Z. Li et al., "Mechanism and prevention of rockburst in steeply inclined and extremely thick coal seams for fully mechanized top-coal caving mining and under gob filling conditions," Energies, vol. 13, no. 6, p. 1362, 2020.

[12] H. P. Xie, H. W. Zhou, D. J. Xue, H. W. Wang, R. Zhang, and F. Gao, "Research and consideration on deep coal mining and critical mining depth," Journal of China Coal Society, vol. 37, no. 4, pp. 535-542, 2012.

[13] P. F. Lyu, X. H. Chen, G. B. Chen, and L. Qiu, "Experimental study on dynamic mechanical responses of coal specimens under the combined dynamic-static loading," Arabian Journal of Geosciences, vol. 13, no. 18, p. 935, 2020.

[14] H. Zhou, F. Meng, C. Zhang, D. Hu, F. Yang, and J. Lu, "Analysis of rockburst mechanisms induced by structural planes in deep tunnels," Bulletin of Engineering Geology and the Environment, vol. 74, no. 4, pp. 1435-1451, 2015.

[15] H. Hossein, H. Felix, A. Catherine, and B. Stefan, "Migrationbased microseismic event location in the schlema-alberoda mining area," International Journal of Rock Mechanics and Mining Sciences, vol. 110, pp. 161-167, 2018.

[16] A. Sainoki and H. S. Mitri, "Simulating intense shock pulses due to asperities during fault-slip," Journal of Applied Geophysics, vol. 103, pp. 71-81, 2014.

[17] R. A. Stewart, W. U. Reimold, E. G. Charlesworth, and W. D. Ortlepp, "The nature of a deformation zone and fault rock related to a recent rockburst at western deep levels gold mine, witwatersrand basin, South Africa," Tectonophysics, vol. 337, no. 3-4, pp. 173-190, 2001.

[18] L. S. Jiang, P. Wang, P. Q. Zheng, H. J. Luan, and C. Zhang, "Influence of different advancing directions on mining effect caused by a fault," Advances in Civil Engineering, vol. 2019, Article ID 7306850, 10 pages, 2019.

[19] Z. Yang, C. Liu, H. Zhu, F. Xie, L. Dou, and J. Chen, "Mechanism of rock burst caused by fracture of key strata during irregular working face mining and its prevention methods," International Journal of Mining Science and Technology, vol. 29, no. 6, pp. 889-897, 2019.

[20] W. Cai, L. Dou, Z. Li, J. He, H. He, and Y. Ding, "Mechanical initiation and propagation mechanism of a thrust fault: a case study of the Yima section of the Xiashi-Yima thrust (North side of the eastern Qinling orogen, China)," Rock Mechanics and Rock Engineering, vol. 48, no. 5, pp. 1927-1945, 2015.

[21] J. G. Lyu, Y. D. Jiang, S. G. Li, S. D. Ren, W. Z. Jiang, and Z. C. Zhang, "Characteristics and mechanism research of coal bumps induced by faults based on extra thick and hard roof," Journal of China Coal Society, vol. 39, no. 10, pp. 1961-1969, 2014.

[22] S. Prusek and W. Masny, "Analysis of damage to underground workings and their supports caused by dynamic phenomena," Journal of Mining Science, vol. 51, no. 1, pp. 63-72, 2015.

[23] W. Cai, L.-M. Dou, J. He, H.-S. Liu, Z.-L. Li, and Y.-l. Ding, "Mechanical genesis of Henan (China) Yima thrust nappe structure," Journal of Central South University, vol. 21, no. 7, pp. 2857-2865, 2014.

[24] L. Dai, Y. Pan, A. Wang, Y. Xiao, and X. Ma, "Experimental study on the self-protection performance of anchor bolts with 
energy-absorbing tails," Rock Mechanics and Rock Engineering, vol. 53, no. 5, pp. 2249-2263, 2020.

[25] L. P. Dai, Y. H. Xiao, Y. S. Pan, A. W. Wang, C. C. Fan, and J. L. Guo, "Mechanical behavior and factors influencing axial splitting energy absorbers and optimized application for rock bolts," Tunnelling and Underground Space Technology, vol. 102, Article ID 103427, 2020.

[26] A. Carpinteri and O. Borla, "Acoustic, electromagnetic, and neutron emissions as seismic precursors: the lunar periodicity of low-magnitude seismic swarms," Engineering Fracture Mechanics, vol. 210, no. S1, pp. 29-41, 2019.

[27] W. F. Brace and J. D. Byerlee, "Stick-slip as a mechanism for earthquakes," Science, vol. 153, no. 3739, pp. 990-992, 1966.

[28] Z. Li, L. Dou, W. Cai et al., "Investigation and analysis of the rock burst mechanism induced within fault-pillars," International Journal of Rock Mechanics and Mining Sciences, vol. 70, pp. 192-200, 2014.

[29] A. Michalisk, "Assessment of rock burst hazard in the approach of a caved longwall to a fault," Przeglad Gorniczy, vol. 23, pp. 387-397, 1977.

[30] X. Chen, W. Li, and X. Yan, "Analysis on rock burst danger when fully-mechanized caving coal face passed fault with deep mining," Safety Science, vol. 50, no. 4, pp. 645-648, 2012.

[31] S. Zhu, Y. Feng, and F. Jiang, "Determination of abutment pressure in coal mines with extremely thick alluvium stratum: a typical kind of rockburst mines in China," Rock Mechanics and Rock Engineering, vol. 49, no. 5, pp. 1943-1952, 2016.

[32] Z. Li, S. C. Yu, W. B. Zhu et al., "Dynamic loading induced by the instability of voussoir beam structure during mining below the slope," International Journal of Rock Mechanics and Mining Sciences, vol. 132, Article ID 104343, 2020.

[33] M. G. Qian, X. X. Miao, and F. L. He, "Analysis of key block in the structure of voussoir beam in long wall mining," Journal of China Coal Society, vol. 19, no. 6, pp. 557-563, 1994.

[34] D. Ma, H. Y. Duan, X. B. Li, Z. H. Li, Z. L. Zhou, and T. B. Li, "Effects of seepage-induced erosion on nonlinear hydraulic properties of broken red sandstones," Tunnelling and Underground Space Technology, vol. 91, Article ID 102993, 2019.

[35] Ł. Wojtecki and P. Konicek, "Estimation of active rockburst prevention effectiveness during longwall mining under disadvantageous geological and mining conditions," Journal of Sustainable Mining, vol. 15, no. 1, pp. 1-7, 2016.

[36] C. Hu, D. Apel, L. J. Sudak, W. V. Liu, and Z. Chu, "Physical investigation on the behaviours of voussoir beams," Journal of Rock Mechanics and Geotechnical Engineering, vol. 12, no. 3, pp. 516-527, 2020. 